\title{
ENTRE NECROPSIAS Y ATESTADOS POLICIALES: MAMORU SHIMIZU Y el Misterio del Dragón Negro
}

Between necropsies and police reports: Mamoru Shimizu and the

Mystery of the Black Dragon

\section{Manuel Zanutelli-Rosas ${ }^{1}$}

\section{RESUMEN}

\begin{abstract}
Esta crónica relata el sangriento crimen de siete miembros de dos familias japonesas, ocurrido el 2 de noviembre de 1944, en Lima. El japonés Mamoru Shimizu fue inculpado y alrededor de él se tejieron diversas hipótesis. Murió en prisión y muchas interrogantes quedaron abiertas.
\end{abstract}

Palabras claves: crimen, japonés, Mamoru Shimizu.

\section{Abstract}

This chronicle reports the bloody crime of seven members of two Japanese families on November 2, 1944, in Lima. Japanese Mamoru Shimizu was incriminated and various hypotheses were woven around him. He died in prison and many questions were left open.

Keywords: crime, Japanese, Mamoru Shimizu.

aso Mamoru Shimizu ocupó durante varias semanas, en los primeros años de la década de 1940 las páginas de todos los periódicos. El sábado 4 de noviembre de 1944, los diarios de Lima y Callao dieron la noticia que en el corralón N³ 344 del jirón Tingo María (Chacra Colorada) se habían cometido varios crímenes horrorosos que hasta ese momento eran atribuidos al japonés Mamoru Shimizu, quien se negaba a admitir su culpabilidad.

Chacra Colorada era un lugar pobre, escasamente poblado. Como zona para vivir no representaba nada, a pesar de los esfuerzos que desde 1921 había desarrollado un grupo de capitalistas a través de una empresa urbanizadora para darle otra fisonomía.

Allí nomás, al lado, estaba el fundo "Breña", que por su ubicación al sur oeste de la ciudad -lejos del comercio, de las iglesias, de las plazuelas, de los cines, de la vida mundanano era fácil de vender, a pesar de la intensa publicidad desarrollada por sus dueños desde

\section{SEPTUPLE GRTMEN CONMOVIO A LMA IMPENETRABLE MISTERIO CUBRIOLA ORGIA DESANGRE}

1 Periodista y escritor. 
1917, quienes lo habían lotizado. Allí fueron a vivir personas de muy escasos recursos económicos que luchaban por tener un techo.

Mamoru era un hombre joven, de baja estatura, de carácter aparentemente apacible y reservado, que había nacido en 1912, en Lima. De 1928 a 1934, se ausentó del país para viajar al Japón y prestó servicio militar en el frente chino. Retornó con su esposa Sumiko el 13 de agosto de 1941 y pasaron a vivir al jirón Cotabambas $\mathrm{N}^{\circ} 329$, sector del cuartel $5^{\circ}$, entre Mapiri y Bambas, a un paso del Parque Universitario.

No está precisada la fecha de su traslado al lugar donde se desarrollaría el drama policial que estremeció a la ciudad.

Tamoto (o Tomotsu), su hermano, llegó al país el 4 de enero de 1939 acompañado de su mujer Hanay, o Hanae, en ese momento de 28 años.
Eran padres de dos mujeres y un hombre: Shimiko, Yoshiko y Tokio, niños que en 1944 tenían 10, 5 y 7 años, respectivamente.

Hanay, por una estancia anterior, conocía la ciudad donde incluso tenía familia. Practicaba el budismo. Estudió corte y confección en una academia. Los Shimizu ocupaban toda una manzana en la que habían construido dos casas separadas por considerable distancia, lo que les permitía estar juntos y lejos a la vez.

Con ellos -con Tamoto y Hanay- vivían su primo Hiromo Tomayashi y su esposa Mika Karide, ambos de religión católica.

Las tres familias eran servidas por Kiyoshi Nayto y su esposa Setsuko, en el Perú desde 1931, según la ficha de identidad del Departamento de Extranjería, Nacionalización e Inmigración del Ministerio de Relaciones Exteriores, que marca el derrotero también

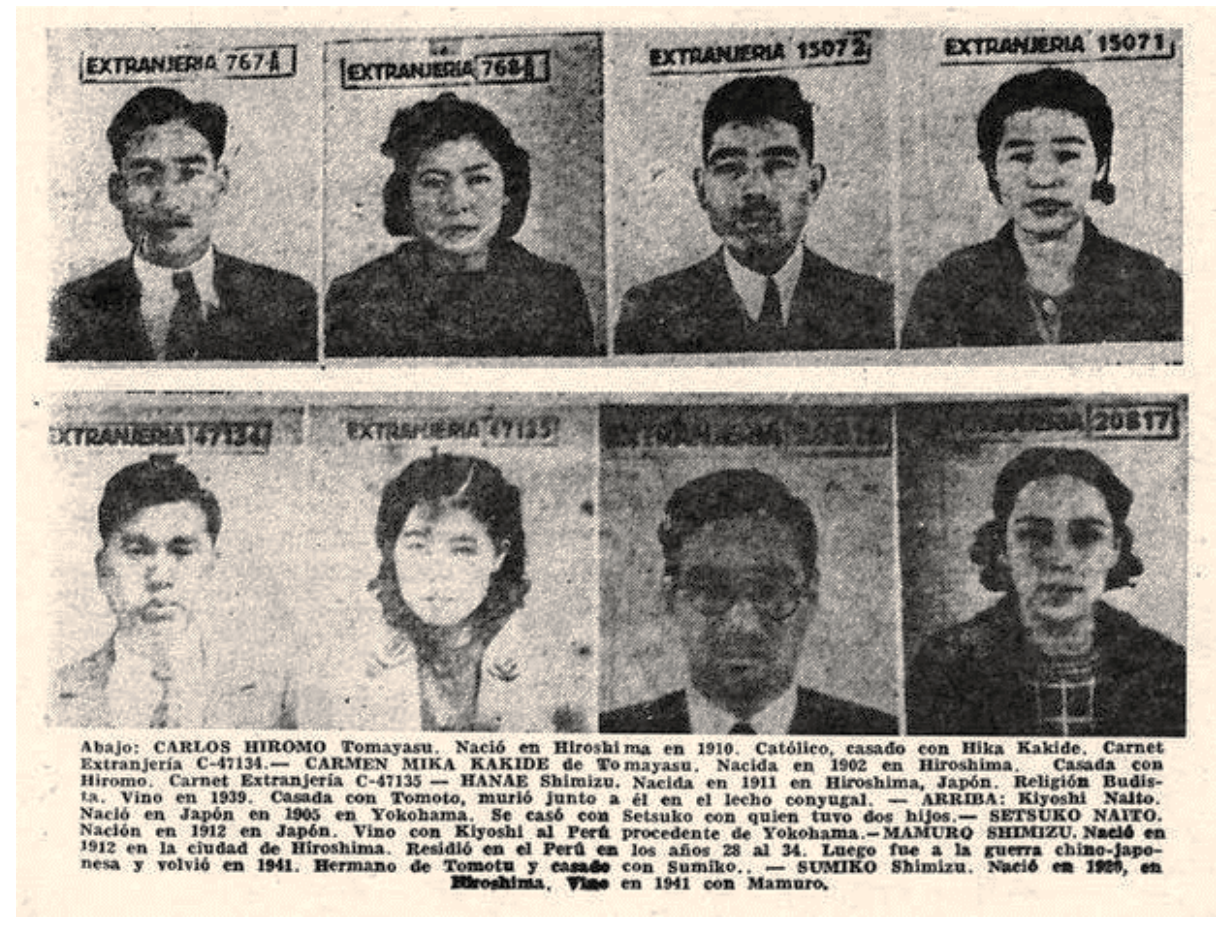

Archivo Histórico El Comercio. 
de los demás implicados. Kiyoshi y Setsuko vivieron por algunos años en la calle del Milagro No 498 con sus dos hijos.

Hiromo vino a la edad de 23 años desde Yokohama en 1933 y, a diferencia de sus familiares, se instaló en Sullana con el fin de realizar actividades comerciales. No tenían mucho tiempo en Lima cuando se originó lo que el periodismo policial llamó "El crimen de la noche de difuntos".

Hasta aquí los personajes de esta tragedia que conmovió a la opinión pública y que dio origen a una serie de especulaciones.

\section{UN RIACHUELO DE COLOR ROJO}

A las siete de la mañana del día 3 de ese mes de noviembre, una pareja de policías que estaba por acabar su ronda en el sector, vio, con asombro, tres cadáveres semidesnudos en el riachuelo que corría a escasos metros del lugar donde habitaban los japoneses. Dieron parte a sus superiores, pero horas después serían descubiertas cuatro víctimas más que, como las anteriores, fueron remitidas a la morgue por orden del juez. Eran Tamoto Shimizu, su esposa y sus tres hijos, además de Hiromo Tomayashi y su mujer. En total: 7 personas. Golpeadas en la cabeza y en el rostro, de manera salvaje, como quien descarga una gran ira, hasta los más curtidos policías quedaron impactados por el espantoso espectáculo, por la escena de sangre y horror.

Hanay Shimizu fue hallada desnuda con "la mejilla derecha a medio devorar por los gallinazos"; presentaba, además, numerosas heridas causadas por sus asesinos.

Interrogado Mamoru respondió que ese día se levantó temprano, a las seis de la mañana, como era su costumbre y se fue en su auto Plymouth con su paisano Kiyoshi Nayto al mercado de Chacra Colorada. A las 6.30 pm estuvieron de regreso. Dijo que en la noche de los sucesos no sintió ruidos y que ni siquiera ladró el perro que dormía afuera de sus habitaciones. No sabía cuáles podían haber sido los móviles que originaron la tragedia ni menos aún quienes eran los asesinos. Naturalmente, la policía no le creyó ni la mitad de sus afirmaciones y continuó sometiéndolo a serios interrogatorios. $\mathrm{Su}$ esposa Sumiko, quebrada por la angustia, hundida en la desesperación, terminaría sin embargo acusándolo de ser el autor de los asesinatos $\mathrm{y}$, con lágrimas, le pidió que confesara, que contase todo. Ella había encontrado en una maleta un saco azul manchado de sangre, que le pertenecía a Mamoru y, aunque él no admitió que era de su propiedad, los miembros de la Brigada Criminal lo obligaron a que se lo probara. Era de su talla, le quedó bien; de todas maneras, eso no constituía una prueba irrefutable, porque alguien podía haberlo manchado con la sangre de las víctimas para inculparlo.

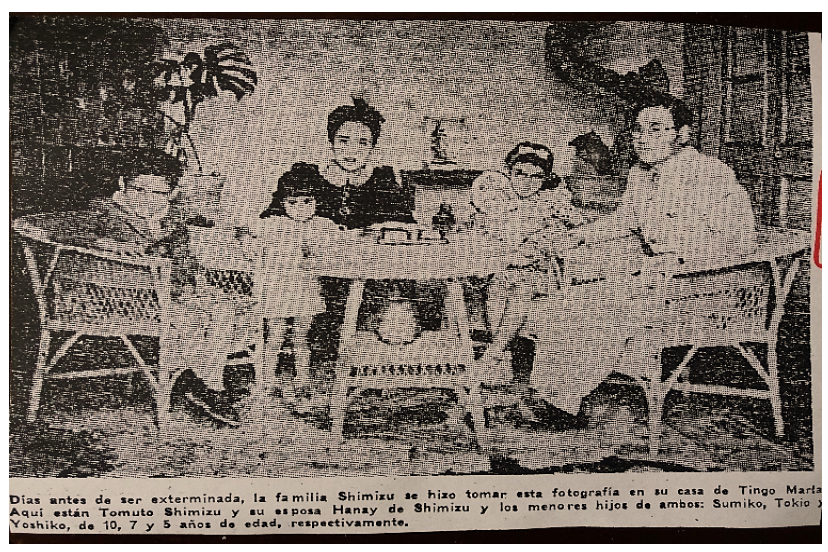

Tamoto Shimizu y Hanai de Shimizu junto a sus tres hijos.

Sumiko recordó que la noche anterior, reunidos los adultos en el comedor de la familia Tomayashi, se originó una fuerte discusión entre Mamoru y Hiromo Tomayashi, primero en inglés y luego en su idioma nativo. Eran una serie de situaciones que Mamoru debía 
explicar; en ellas podía estar el hilo conductor de la verdad.

Mamoru, en un callejón sin salida, confesó; se declaró único autor de la matanza y relató cómo se habían desarrollado esos desgraciados sucesos.

\section{Dos frascos de pastillas de Veronal}

Dijo que los hizo dormir con pastillas de Veronal ${ }^{\circledR}$ (barbital sódico). Compró dos frascos de diez comprimidos cada uno y utilizó once. La policía averiguó que la mitad de uno era suficiente para sumir en un profundo sueño a una persona. El Veronal habría sido echado en los tallarines que preparó la esposa de Mamoru (sin intervención de ella), lo que quiere decir que las tres familias cenaban juntas. Sumiko informó después que no los comió porque "les notó cierta acidez".

Retirados a sus respectivas habitaciones, Mamoru dejó pasar las horas y cuando comprobó que todos dormían empezó su macabra tarea. Primero mató a su hermano Tamoto, luego a su cuñada Hanay y seguidamente a los tres niños. Al terminar con este matrimonio se dirigió a las habitaciones de Hiromo Tomayashi y Mika Karide. A cada una de sus víctimas las golpeó con un tablón, y una a una las fue depositando en una acequia. Su tarea -macabra, horrorosa- empezó a las doce de la noche del 2 de noviembre, 1944, y terminó a las 5.30 de la mañana del día 3. La ropa de cama y las prendas interiores de sus víctimas (sábanas, frazadas, fundas, pijamas, etc.) las guardó en seis costales. Todo, volvió a decir, lo hizo solo.

Tal fue su versión. Pero, ¿hasta qué punto era cierta? ¿En qué medida era veraz su historia? ¿A quién pretendía engañar? ¿Matar a su hermano, a su cuñada y a sus sobrinos?
La saña, la ira que puso, supuestamente, Mamoru en el asesinato de su hermano se refleja en las conclusiones del protocolo de necropsia.

Que la acción violenta se dejó sentir sobre la cabeza. Que en la cabeza se encontraron lesiones de los elementos superficiales, lesiones óseas fracturarias, desgarraduras de las meninges, hemorragias de las mismas y atrición del encéfalo, lo que revela los recios golpes que en vida recibiera a nivel del segmento cefálico. Que las lesiones traumáticas recibidas eran graves y harían imposible la supervivencia después de producidas, es decir, eran incompatibles con la vida en forma inmediata. Que el victimario utilizó para asestar dichos golpes sobre la cabeza de su víctima un instrumento pesado, contundente, manejado con bastante intensidad y rapidez. Que parece probable que la muerte se ha producido cuando el mencionado Shimizu dormía bajo los efectos de una sustancia estupefaciente propinada en dosis bastante alta, como para producir el sueño en forma intensa. (Morgue Central de Lima. Protocolo de Autopsia N9900. Fecha: 3 de noviembre de 1944. Archivo General de la Nación.)

Se discutió mucho sobre este caso. Mamoru no era un hombre fuerte; por lo tanto, arrastrar uno a uno a cuatro adultos y tres menores hacia la acequia no era tarea que se pudiera ejecutar tan fácilmente por una sola persona.

\section{La sociedad secreta El Dragón Negro}

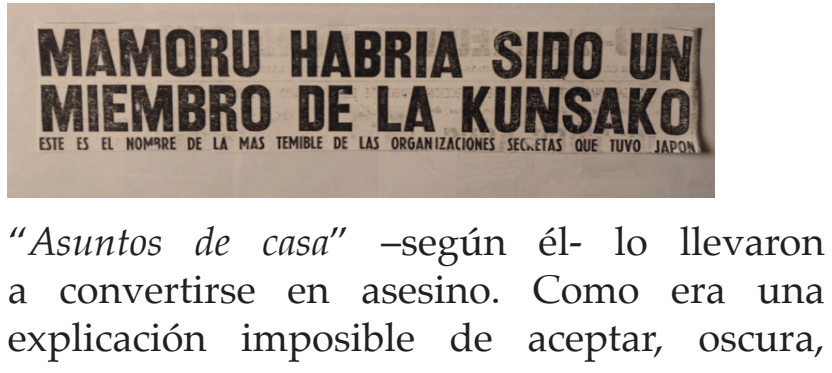

Acta Herediana vol. 64, N 1, enero 2021 - junio 2021 
que prácticamente dejaba en el limbo a los investigadores, porque no quedaban claros los móviles, los periódicos dejaron correr la versión, fantasiosa o no, de la presencia de una sociedad secreta: El Dragón Negro, que había castigado así a los esposos Tomayashi y Shimizu por alguna falta cometida. Se consideraron tres posibilidades:

- Que Mamoru fuese uno de los ejecutores de la sentencia.

- Que hubiese facilitado el ingreso de los asesinos.

- Que actuó como un espectador de los hechos.

No olvidemos que eran los años de la Segunda Guerra Mundial, de las atrocidades japonesas en las ciudades ocupadas por su ejército, y que era frecuente hablar de espías. ¿Recibieron Tamoto Shimizu y su paisano Hiromo Tomayashi órdenes de cumplir una misión y fracasaron, o se negaron a ejecutarla? En el registro que se hizo en la parte posterior del corralón, en el sector que daba a la calle Manoa $\mathrm{N}^{\circ} 242$, donde antes estuvo una carbonería, se encontraron revistas "en diversas lenguas", fotografías familiares, "una serie de planos y cartas geográficas", así como "documentos escritos en japonés"; también hallaron un mimeógrafo y una cámara fotográfica.

No hubo motivaciones de robo. Eso quedó descartado, la pérdida de dinero y alhajas se produjo después, cuando la policía se hizo cargo de las investigaciones.

En la inspección ocular las autoridades encontraron, en una caja de fierro, dinero en moneda nacional y en dólares, ascendente en conjunto a 40 mil soles, más 364 soles que se hallaron guardados en un armario. Mamoru alegó que en la caja fuerte de su hermano se guardaban 200 mil soles, y que a causa de los registros efectuados habían desaparecido. Esto dio motivo a que se abriera una instrucción contra dos investigadores, acusados de apropiación ilícita.

No se halló ninguna joya. El diario La Crónica del 16 de noviembre de ese año decía que cómo era posible, tratándose de familias acomodadas, que las mujeres "no tengan siquiera un insignificante arete". Y, lanzaba esta pregunta, como para que todos sus lectores también se la formularan: “¿Dónde están las alhajas?".

La familia Shimizu tenía una situación económica holgada. El interior de las casas estaba arreglado de manera armoniosa, "con confortables, vitrinas en las que se advierte figuras de porcelana que representan geishas y otros muebles lujosos". Contaban también con "un hermosísimo jardín estilo japonés, dotado de diversidad de exóticas plantas propias de Japón; vegetales trepadores y rastreros que se confunden con enormes peñascos que han sido colocados de ex profeso superpuestamente, dándole así al jardín un declive natural que termina con un amplio estanque de aguas cristalinas dividido en varias secciones en cada una de las cuales viven pececillos de diversidad de colores". En dos habitaciones había acuarios "que contienen peces diminutos que nadan entre algas y la arena que se ha colocado". ( $\mathrm{La}$ Crónica 5-11-1944, p. 15).

La policía halló "ropa bien cuidada y maletas finas", así como huacos "de diferentes tamaños y formas, pertenecientes a la civilización Chimú y una pequeña biblioteca".

¿De dónde tanto dinero? ¿Cómo lo acumuló la familia Shimizu? Mamoru y Tamoto tenían un hermano de nombre Naburu Mizuta, fundador de la negociación "Mizuta y Cía", quien durante veinte años se había dedicado 
a la venta de carbón. A consecuencia de la guerra mundial había sido deportado a los Estados Unidos. Ellos en calidad de familiares directos continuaron con esas actividades. En la Guía Lascano de 1944-1945 hay un aviso de la sección Gremios (pág. 1284) que dice:

Depósito de carbón

Productos peruanos S.A Venta de

Carbón de palo- De ruma- Cernido-

Carbonilla- Leña de algarrobo-Tizones-

Carbón de piedra-Fragua-Coke y sacos vacíos.

Oficina: Padre Jerónimo $\mathrm{N}^{\circ} 478$

Teléfono $\mathrm{N}^{\circ}$ 32120, apartado 2356

Depósito: Manoa Nº 248 (Chacra Colorada).

Teléfono N 11691, Lima, Perú

\section{EN LA MANANA DE HOY SE INIERROGARA] \\ ASUMIKOSHIMIZU.}

Lo que sí quedó establecido fue la mala relación entre los hermanos Shimizu. La esposa de Mamoru dijo que su cuñado era una persona buena, aunque de carácter violento. Solía discutir con Mamoru a quien acusaba de "ocioso y negligente". Parece que Tamoto, arbitrario, abusaba de su mayoría de edad (Mamoru nació en 1912 y él en 1904) y pretendía que por tal razón debía obedecérsele en todo. En La Crónica (13-11-1944) se recogió la versión que Tamoto le prohibió a su hermano sentarse a la mesa a comer con su familia, lo mismo que a su cuñada Sumiko. Otro diario (El Comercio 13-11-1944) comentó que "lo posponía en todo y no le daba sino ciento treinta soles, casa y comida; que poco después lo arrojó de su casa, asignándole para vivir la suma de doscientos soles". Tamoto se negaba a hacer el reparto de los bienes comunes y quería "quedarse con todo". El barrio los calificó como "gente de nobles sentimientos, caritativa, en todas las oportunidades; daba socorro a los menesterosos y trabajo a los que lo necesitaban".

\section{¿Qué pena correspondía?}

Sometido a juicio, Mamoru fue condenado a veinticinco años de penitenciaría. Su proceso se inició el 21 de setiembre de 1948 en el Segundo Tribunal Correccional, que presidía el doctor Leoncio Serpa e integraban Pedro Gazats y Napoleón Valdez Tudela; y, concluyó el 17 de noviembre del citado año.

Mamoru negó haber sido el asesino y forjó toda una historia que nadie creyó: ni los magistrados ni el numeroso público que seguía cada una de las audiencias. Dijo que cuatro hombres con el rostro cubierto lo atacaron "al salir al exterior a averiguar por qué ladraban los perros". Atado y amordazado, nada pudo hacer en defensa de su familia; y, realizada la masacre, lo obligaron a ayudar en el traslado de los cadáveres.

En La Crónica del 5 de noviembre de 1948, el redactor encargado de cubrir el proceso, escribió: "persistimos en nuestra teoría de que Mamoru conoce la identidad de los asesinos, los que obrarian en obediencia a órdenes emanadas posiblemente desde el Japón, ya que Tomatsu Shimizu traicionó la causa de la patria y se negó a seguir colaborando con las organizaciones secretas japonesas".

LIBERADO DE CULPA, FUE PUESTO EN

UIBERTAD EL NIPON" KIYOSHI NAYTO

El mayordomo Kiyosi Nayto, quien fue defendido por el doctor Pedro Jiménez Guzmán, quedó en libertad incondicional al no haber tenido ninguna participación en los crímenes. Sumiko, la infortunada mujer de Mamoru, se vio, de la noche a la mañana, sola en un país extraño y con escaso conocimiento 
del idioma, sin posibilidades de regresar a su país, en ese momento en guerra. Cuando se produjo el crimen, ella tenía apenas tres años de residencia en el Perú. ¿Era inocente? ¿Verdaderamente, estaba libre de culpa? No comió los tallarines donde presuntamente se habían disuelto las pastillas de Veronal. En consecuencia, tuvo o debió de tener un sueño llamémosle "normal". ¿Cómo entonces no sintió nada?

Nunca encajó, además, en el sentido común de los integrantes dela Brigada Criminal el caso del saco manchado de sangre que, supuestamente, usó Mamoru el día o la noche de los asesinatos. ¿Quién se pone saco para matar? Sumiko debió de haber sido lo que popularmente se denomina una "mosquita muerta". Se empeñó en demostrar la culpabilidad de su marido con el afán desmedido de concentrar las miradas y la búsqueda en torno de él. Rara manera de comportarse de una esposa. No hubo ejecutores, parecería haber sido su grito desesperado.

Nada de lo que dijo Mamoru en el proceso fue aceptado por los miembros del Tribunal, y la sentencia de 25 años de internamiento se basó en la confesión formulada por el acusado ante el Juez Instructor, que el abogado Víctor Modesto Villavicencio, a cargo de la defensa, rechazó por considerarla viciada. En su concepto había sido fruto de la presión moral que se había ejercido contra su patrocinado.

En una fase del juicio, Mamoru había dicho que se declaró autor de los crímenes porque los investigadores lo amenazaron con internar en la cárcel a su esposa e hijita. El agente fiscal Leonidas Ponce Sobrevilla le replicó que cómo entonces realizó la reconstrucción de los crímenes y respondió que sólo cumplía las órdenes del juez.
En la última audiencia (la de la condena), el acusado insistió en su inocencia. "Si acaso hubiera cometido lo que se me acusa, yo no estaría aqui, me hubiera hecho el harakiri", manifestó.

Quedó una sensación de duda sobre el fallo, porque no había arrojado "luz definitiva sobre este drama".

Sumiko, tres años después del juicio de su esposo, decidió irse del Perú. Y, Noriko, la hija de ella y de Mamoru, creció en el Japón sin noticia de los sucesos que había protagonizado su padre. En su libro Los Imperios del Sol (Lima, 1996, pág. 216) dice Guillermo Thorndike que "realizó estudios universitarios" y que "viaja al Perú regularmente".

El asesino de Tingo María, así fue llamado, ocupó por muchos años la celda $\mathrm{N}^{\circ} 36$ de la Cárcel Central de Varones, que estaba en el Paseo de la República, donde actualmente están el Hotel Sheraton y el Centro Cívico. Callado, solitario, evitaba toda clase de tratos con sus compañeros de prisión, a pesar de trabajar como peluquero. Padecía de asma, lo que al parecer le fue fatal.

El 4 de junio de 1959 se hizo poner una inyección de Vitacose que le chocó y terminó por causarle la muerte.

En la necropsia que se le hizo en la Morgue Central de Lima se anota que el cadáver fue remitido por la 5ta. Comisaría "para investigar la causa de su muerte". Resultado: edema pulmonar agudo. Mamoru medía 1.60 $\mathrm{m}$ y no era una persona físicamente fuerte. ¿Cómo pudo alegar que él solo cargó los siete cadáveres hacia el brazo del río cercano a su casa? ¿Con qué energía? La Morgue Central, en un evidente y censurable descuido, dejó el certificado sin las firmas del médico jefe y del director. 
Lo enterraron en el cuartel San Fernando C-54, del Cementerio Presbítero Maestro. Acompañaron el cortejo 51 personas, entre
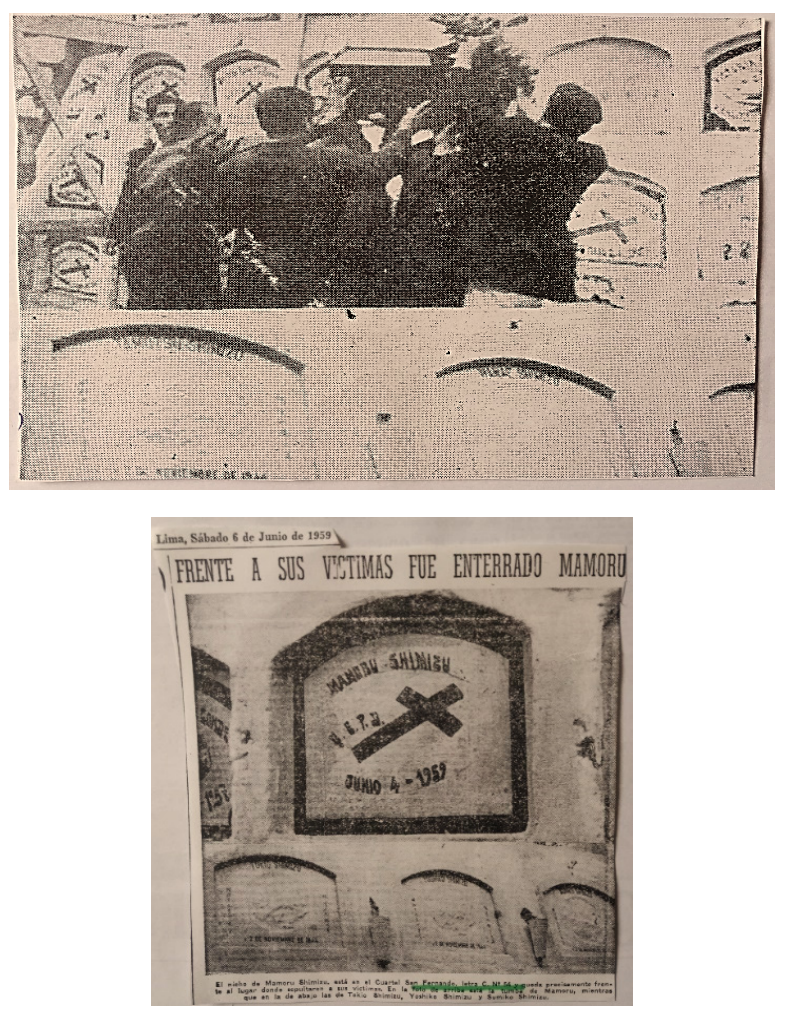

Depósito del féretro y nicho de Mamoru Shimizu en el Cementerio Presbítero Maestro. éstas doce nipones y algunos funcionarios del penal. Una de las personas que cargaron el ataúd fue su antiguo empleado Kiyoshi Nayto. Con motivo de su deceso se recordó que el fiscal de la época ordenó que se abriera instrucción "a los altos jefes de investigaciones que intervinieron en el descubrimiento del crimen" de 1944.

En 1955, ya retirados, dijeron que la caja fuerte la llevaron a la Prefectura y al ser abierta solo encontraron 20 mil soles.

Así se desarrolló el caso, como para meditarlo.

\section{Correspondencia}

Manuel Zanutelli

manuel.zanutelli@yahoo.com

Fecha de recepción: 31-10-2020.

Fecha de aceptación: 11-01-2021.

Conflicto de interés: ninguno, según el autor.

Financiamiento: por el autor. 